\title{
Analysis of lightning outliers in the EUCLID network
}

\author{
Dieter R. Poelman ${ }^{1}$, Wolfgang Schulz ${ }^{2}$, Rudolf Kaltenboeck ${ }^{3}$, and Laurent Delobbe ${ }^{1}$ \\ ${ }^{1}$ Royal Meteorological Institute of Belgium, Brussels, Belgium \\ ${ }^{2}$ OVE-ALDIS, Vienna, Austria \\ ${ }^{3}$ Austro Control, Innsbruck, Austria \\ Correspondence to: Dieter R. Poelman (dieter.poelman@meteo.be)
}

Received: 9 May 2017 - Discussion started: 29 June 2017

Revised: 7 September 2017 - Accepted: 17 October 2017 - Published: 27 November 2017

\begin{abstract}
Lightning data as observed by the European Cooperation for Lightning Detection (EUCLID) network are used in combination with radar data to retrieve the temporal and spatial behavior of lightning outliers, i.e., discharges located in a wrong place, over a 5-year period from 2011 to 2016. Cloud-to-ground (CG) stroke and intracloud (IC) pulse data are superimposed on corresponding 5 min radar precipitation fields in two topographically different areas, Belgium and Austria, in order to extract lightning outliers based on the distance between each lightning event and the nearest precipitation. It is shown that the percentage of outliers is sensitive to changes in the network and to the location algorithm itself. The total percentage of outliers for both regions varies over the years between 0.8 and $1.7 \%$ for a distance to the nearest precipitation of $2 \mathrm{~km}$, with an average of approximately $1.2 \%$ in Belgium and Austria. Outside the European summer thunderstorm season, the percentage of outliers tends to increase somewhat. The majority of all the outliers are low peak current events with absolute values falling between 0 and $10 \mathrm{kA}$. More specifically, positive cloud-toground strokes are more likely to be classified as outliers compared to all other types of discharges. Furthermore, it turns out that the number of sensors participating in locating a lightning discharge is different for outliers versus correctly located events, with outliers having the lowest amount of sensors participating. In addition, it is shown that in most cases the semi-major axis (SMA) assigned to a lightning discharge as a confidence indicator in the location accuracy (LA) is smaller for correctly located events compared to the semimajor axis of outliers.
\end{abstract}

\section{Introduction}

Present-day lightning location systems (LLSs) are the result of continuous development over the years with improved location accuracy (LA), peak current estimation and type classification for each observed lightning event. However, despite the great progress that has been made in the determination of those properties amongst others, occasionally some events remain poorly determined by the LLS. For instance, the uncertainty of the measurements related to a low peak current discharge tends to be larger than it is for a high peak current event. In addition, it is still common practice to categorize positive cloud-to-ground (CG) strokes with estimated peak currents smaller than five or $10 \mathrm{kA}$ as intracloud (IC) pulses since those are more likely to be of IC nature (Cummins et al., 1998, 2006; Wacker and Orville, 1999a, b; Jerauld et al., 2005; Orville et al., 2002; Biagi et al., 2007). However, not all the properties are of equal importance for the different users of lightning data. Depending on the customers' application of the LLS data, different performance features are more important, while others are less important; e.g., power utilities normally do not care about the IC detection efficiency (DE) of an LLS, whereas the quality of the CG data is of utmost importance. On the other hand, aviation control and meteorological services which often trigger warning messages based on LLS data favor a good DE of CG and IC events coupled to a minimum of events located in a completely wrong position. It is therefore necessary to gain a thorough understanding of the LLS at hand.

During recent years the performance of LLSs has received more and more attention (Nag et al., 2015). A direct method to determine the quality of a network, and therefore the values assigned to each lightning event, is by comparing the 


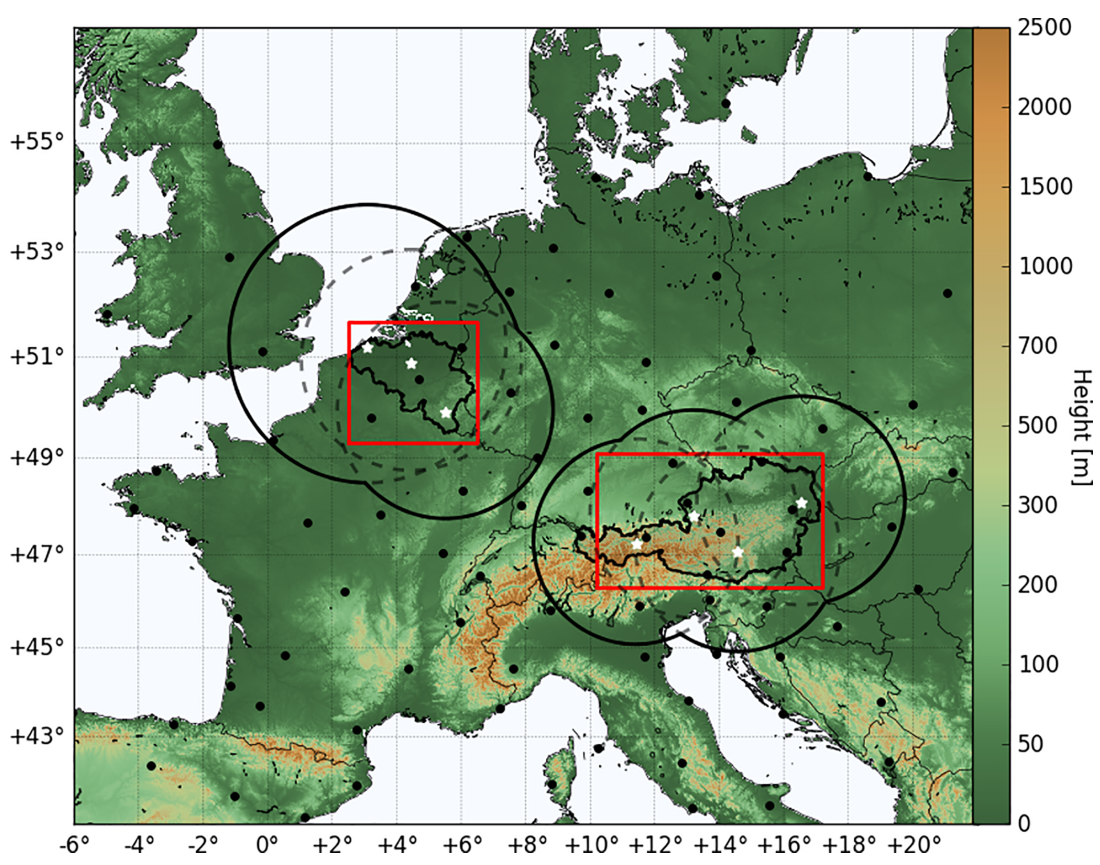

Figure 1. The locations of the EUCLID sensors in the domain are indicated (black dots), as well as the positions of the radars (white stars) together with the respective collective detection range in Belgium and Austria. The red boxes indicate the two areas that are used in this study.

data against so-called ground-truth observations. Those observations provide valuable information on the $\mathrm{DE}$, location accuracy and in some cases even the peak current estimates retrieved from an LLS. This is done for instance by examining direct lightning strikes to instrumented towers (Diendorfer et al., 2000a, b; Pavanello et al., 2009; Romero et al., 2011; Schulz et al., 2012, 2013; Cramer and Cummins, 2014; Azadifar et al., 2016) through the use of rocket-triggered lightning (Jerauld et al., 2005; Nag et al., 2011; Mallick et al., 2014a, b, c) and/or by recording lightning strikes with highspeed video and E-field (electric field) measurements in open field (Biagi et al., 2007; Poelman et al., 2013a; Schulz et al., 2016). Although they are the best methods for retrieving robust information of a networks' performance, they are quite labor intensive when used to acquire a large enough dataset for a statistically reliable output. Other methods exist, such as the intercomparison of different LLSs within regions of overlapping coverage (Said et al., 2010; Pohjola and Mäkelä, 2013; Poelman et al., 2013b). However, the main disadvantage of those studies is the assumption that one network is the ground truth. In reality this is hardly the case for any existing LLS, except maybe for the short-baseline lightning mapping arrays (Rison et al., 1999; Thomas et al., 2004; van der Velde et al., 2013; Defer et al., 2015).

In this paper lightning data are combined with radar precipitation observations to analyze the temporal and spatial behavior of lightning outliers in two topographically different regions in Europe. Lightning outliers are sometimes also referred to in the literature as fake or ghost strokes and can be the result of signal interferences from power lines, radio frequencies, or other site-specific disturbances or are simply misplaced events by the location algorithm. The results presented here are obtained by combining lightning observations from the European Cooperation for Lightning Detection (EUCLID) network with radar precipitation data in Belgium and Austria, as described in Sect. 2. The results of the analysis are presented in Sect. 3 and summarized in Sect. 4.

\section{Data and methodology}

\subsection{Lightning location data}

The European Cooperation for Lightning Detection network has been operational since 2001 and processes as of January 2017 in real-time data of 164 sensors to provide European-wide lightning observations of high and nearly homogeneous quality (Schulz et al., 2016; Poelman et al., 2016). All of the sensors operate over the same lowfrequency (LF) range and provide amongst others timing and angle information. The individual raw sensor data are sent in real time to a single processor, calculating the electrical activity at any given moment. The locations of the EUCLID sensors are displayed in Fig. 1. The network has been tested continuously over the years against ground-truth data from direct lightning current measurements at the Gaisberg tower in Austria (Schulz et al., 2016), Peißenberg tower in Germany (Heidler and Schulz, 2016) and Säntis tower in Switzerland (Romero et al., 2011; Azadifar et al., 2016) as well as data 

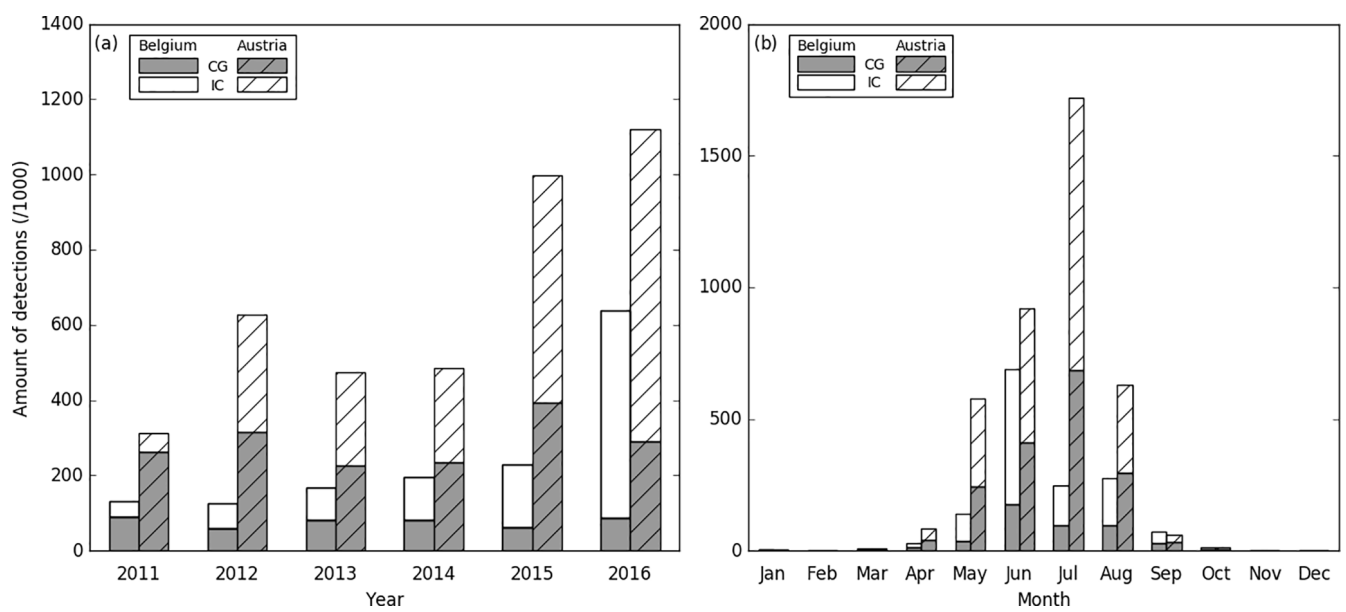

Figure 2. Distribution of the (a) annual and (b) monthly CG and IC counts as observed within the areas indicated over Belgium and Austria in Fig. 1.

from E-field measurements and video recordings in Austria, France and Belgium (Schulz et al., 2016). The latest comprehensive performance analysis of the EUCLID network based on those measurements revealed that the flash and stroke DE for negative CG discharges in different regions of the EUCLID network are greater than 93 and $84 \%$, respectively, while for positive events those are greater than 87 and $84 \%$, respectively (Schulz et al., 2016). To retrieve the latter values, only those strokes that match certain quality criteria such as $\chi^{2}$ are used in the analysis, which is a measure for the agreement between the different sensor measurements and the semi-major axis (SMA) of the confidence ellipse, and received a correct stroke classification as CG by the central processor. Those strict criteria, as well as temporary sensor outages during the measurements campaign, can impact the DE estimates given in Schulz et al. (2016). In addition, Schulz et al. (2016) showed that the LA dropped steadily over the years down to the present LA in the range of $100 \mathrm{~m}$ within the majority of the network. Note that in Schulz et al. (2016) ground-truth observations are collected in Austria and Belgium, the same regions of the EUCLID network which are studied in this paper.

During the time period under consideration, significant changes in the EUCLID network regarding DE and LA were made (Schulz et al., 2016). Those are related to new sensor technology, timing error corrections and a new location algorithm which can influence the outlier behavior. One would think sensor upgrades have always a positive influence on a network's performance. While this is generally true in the long run, the upgrades can cause temporary problems in the beginning since those sensors are awaiting calibration. This is especially true for some sensors in Italy in 2014. From the day of the setup until the sensors were calibrated, those sensors were configured to provide timing information only. However, timing-only sensors often increase the number of outliers if they are used in solutions determined by two or three sensors only.

Figure 2a plots the annual distribution of the total stroke count over the years 2011 until 2016, as observed within the red boxes in Fig. 1. As expected, the CG distribution experiences a natural annual variability in Belgium as well as in Austria. With regard to the IC detections, one notices a sharp increase in 2015 and 2016. This increase is not climatological in nature, but is attributed to the increased amount of LS700x sensors in EUCLID and its capability to detect IC pulses in the low-frequency domain. The distribution of the total monthly stroke count is shown in Fig. 2b. A peak in activity is observed in June and July for Belgium and Austria, respectively. For both regions about $95 \%$ of all the observed lightning activity occurs between May and September.

\subsection{Weather radar data}

The weather radar data of the Royal Meteorological Institute of Belgium (RMIB) and of Austro Control in Austria are used in this study. Figure 1 shows the locations (white stars) and coverage (dashed lines) of the individual radars as well as the limit of the composite as the outer contour of all the radars (solid lines). The use of radar composites is preferred over the individual radar observations since individual radar observations can be hampered by shielding effects. This is true especially in mountainous regions such as the Alps in Austria, limiting the detection range where the radar data are still considered of sufficient quality. Additionally, since the height of the radar beam above ground increases with increasing distance from the radar, precipitation can be underestimated or even undetected at far range by overshooting when precipitation is produced below the height of the lowest radar beam. Therefore, to eliminate the latter effect, the two geographical areas in this study are limited to the red boxes as indicated in Fig. 1. 
The composite radar reflectivity threshold is set at $12 \mathrm{dBZ}$. Following the $Z=200 \cdot R^{1.6}$ relationship from Marschall and Palmer (1948), with $Z$ being the reflectivity and $R$ the rain rate, this threshold corresponds to a rain rate of $0.2 \mathrm{~mm} \mathrm{~h}^{-1}$ below which the rain rates are set to zero in this study. This low reflectivity threshold helps to detect convective clouds relevant for lightning generation even in weak cell cores from winter events or upper areas of thunderstorms at far ranges from the radar site.

\subsubsection{Belgium}

The radar composite used at RMIB consists of three radars. RMIB owns and operates two of them: the radar at Wideumont in the southeast of Belgium and the radar in Jabbeke located near the west coast which has only been operational since 2013. The third weather radar at the center of the composite is located at the airport in Zaventem near Brussels and is operated by Belgocontrol, which is in charge of the safety of civil aviation. All of the radars are C-band Doppler radars performing a multiple elevation reflectivity scan every $5 \mathrm{~min}$ with a resolution of $1^{\circ}$ in azimuth and $500 \mathrm{~m}$ in range for Jabbeke and Zaventem and $250 \mathrm{~m}$ in range for Wideumont. The maximum range is $300 \mathrm{~km}$ for Jabbeke and $250 \mathrm{~km}$ for Zaventem and Wideumont. A Doppler filter for clutter elimination is used for the three radars and an additional polarimetric fuzzy logic filter is used for Jabbeke. For each radar, a 2-D precipitation product is derived from the volume reflectivity data. The height of those individual products corresponds to $1500 \mathrm{~m}$ above sea level. A composite is subsequently produced from these 2-D products, taking for each pixel the maximum value of the radars covering this pixel. For more information on the validation of the Belgian composite, the interested reader is referred to Goudenhoofdt and Delobbe (2016).

\subsubsection{Austria}

Austro Control, the Austrian civil air service provider, operates five EEC (Enterprise Electronics Corporation) C-band polarized Doppler weather radars in Austria, of which four of them are used in this study. Two of the radar sites are located in the foothills of the Alps close to Vienna and Salzburg (Rauchenwarth and Feldkirchen), while the other two radar sites are situated in the west and south of Austria at mountaintops above $2000 \mathrm{~m}$, close to Innsbruck and Klagenfurt (Patscherkofel and Zirbitzkogel). The underlying volume scan contains 16 elevations ranging between -1.5 and $67^{\circ}$ up to a range of $224 \mathrm{~km}$. Doppler and statistical clutter filters are applied before creating a maximum surface projection of reflectivity which combines the strongest return from each elevation level. The resulting Austrian composite uses the maximum reflectivity in horizontal extent which is provided by one of the four radars to avoid the shielding effects of the Alps. Temporal and spatial resolution is

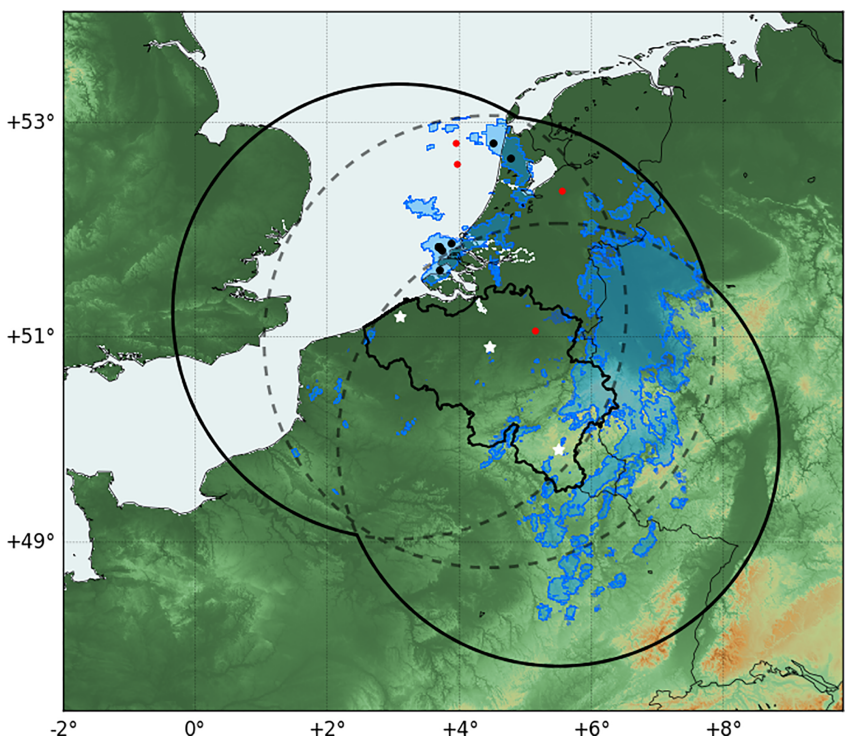

Figure 3. Example of a 5 min precipitation field superimposed with the lightning events within the time interval. The correctly located events are indicated as black dots, whereas the derived outliers are plotted in red. For clarity the underlying precipitation field has been given the same value above the applied threshold of $0.2 \mathrm{~mm} \mathrm{~h}^{-1}$ everywhere.

$5 \mathrm{~min}$ and $1 \mathrm{~km}$, respectively. For more details, the interesting reader is referred to Kaltenboeck and Steinheimer (2015) and Kaltenboeck (2012a, b). It is important to note that the Austrian weather radar network was upgraded between 2011 and 2013, during which the individual radar gains were modified. This adaptation of the gain could easily influence to some degree the findings in this paper.

\subsection{Methodology}

To account for border effects of the radar observations as mentioned in Sect. 2.2, only lightning events within the red boxes as indicated in Fig. 1 are used. Those regions correspond approximately to the area where two or more radars participate in the radar image with sufficient distance from the border. Subsequently, CG strokes and IC pulses with timestamps that fall within the start and end time of the radar scan are superimposed on the corresponding 5 min radar precipitation fields. In order to have overall homogeneous coverage of the weather radar data, only the time steps for which all the radars within the composites were in operation were used. An event is then categorized as an outlier when no precipitation within a certain distance has been observed. The distance at which an event is classified as an outlier is chosen arbitrarily. Different runs are performed by applying a distance $\Delta r$ of 2,5 and $10 \mathrm{~km}$. An example of this method is visualized in Fig. 3. All the lightning events are superimposed as black dots, whereas the retrieved outliers are in red for clarity. Note that this method is supposed to give a lower 

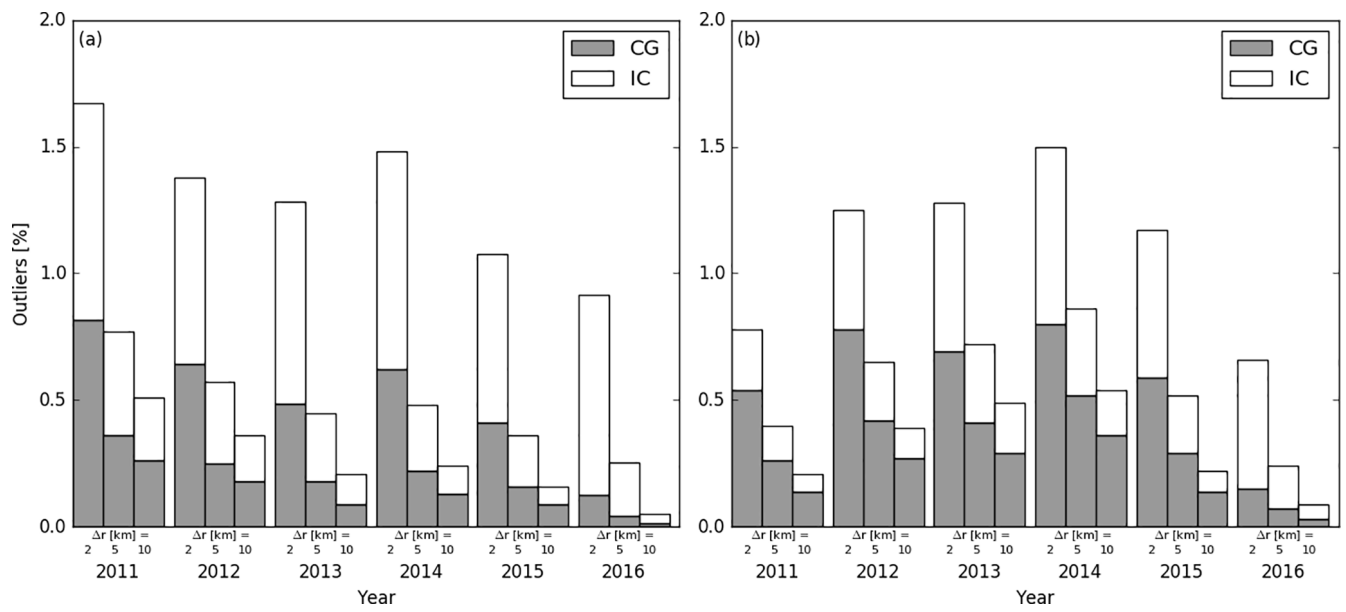

Figure 4. Annual variation of outliers in (a) Belgium and (b) Austria, based on cloud-to-ground (CG) and intracloud (IC) events, for search radii of 2,5 and $10 \mathrm{~km}$.

limit of the percentage of outliers because some of the outliers will, by chance, be placed in a region with radar reflectivity larger than $12 \mathrm{dBZ}$. In the remainder of the paper, explanation of the results is based on the findings for a search radius $\Delta r$ of $2 \mathrm{~km}$ unless otherwise stated explicitly.

\section{Results}

The overall annual percentage of outliers for CG strokes and IC pulses relative to the total number of events, as a function of $\Delta r$ between the event location and the nearest precipitation, is plotted in Fig. 4 for Belgium and Austria. There are several similarities and differences between the two areas. For example, the total percentage of outliers is of the same order of magnitude for both regions and varies between 0.8 and $1.7 \%$ throughout the years for an adopted $\Delta r$ of $2 \mathrm{~km}$. It is clear that choosing a larger $\Delta r$ decreases the percentage of outliers, and vice versa, while maintaining the same annual trend. The percentage of the total outliers averaged over 6 years in Belgium and Austria is approximately $1.2 \%$. In Belgium on average $0.5 \%$ of the outliers are of CG type and this value increases up to $0.9 \%$ in the case of IC, whereas in Austria the level of CG outliers is only slightly higher than that of IC outliers, i.e., $0.8 \%$ for CG with respect to $0.5 \%$ in the case of IC. Shorter baselines in Austria compared to Belgium could be a reason for this discrepancy. The significantly higher number of outliers in Belgium in 2011 compared to Austria can be attributed to a timing-only sensor located close to Belgium (The Hague) and another sensor in the Netherlands which was moved and afterwards operated for a longer time period with deactivated angle information (Roermond). From our experience, sensors providing only time information often cause additional outliers. For the vast majority of the sensors which provide angle and time information those measurements have to be consistent since coherence between the latter two reduces the number of outliers. The level of outliers from 2012-2014 is roughly the same for both areas. The lowest level of CG outliers is found in 2016 in both areas. In addition, it is worth mentioning that in Belgium and Austria the majority of the CG outliers are single stroke flashes, while only a minority of the CG outliers belong to a flash with multiplicity larger than one. One could say that, assuming a stable radar network, the variation in the percentage of outliers over the years reflects the status of the lightning location network in a certain area. Hence, continuous monitoring of the outliers has the possibility to pick up potential problems in the network, which can be relevant for future automatic forecast applications.

The left panels in Fig. 5 display the 6-year mean annual total lightning event (CG strokes + IC pulses) density on a $10 \times 10 \mathrm{~km}^{2}$ grid in Belgium and Austria. For Belgium, densities vary between 0.8 and 11 events $\mathrm{km}^{-2} \mathrm{yr}^{-1}$ with a median value of 3.4 events $\mathrm{km}^{-2} \mathrm{yr}^{-1}$ at $10 \mathrm{~km} \times 10 \mathrm{~km}$ resolution. Overall the densities in Austria are somewhat higher compared to Belgium, resulting in a median value of 4.4 events $\mathrm{km}^{-2} \mathrm{yr}^{-1}$. The highest total lightning densities are found towards the southeast of Austria with a maximum of 22 events $\mathrm{km}^{-2} \mathrm{yr}^{-1}$. Figure $5 \mathrm{c}$ and d reveal the spatial distribution of the percentage of total outliers as observed between 2011 and 2016. In Belgium, values range from 0.2 to $3.3 \%$. The distribution of outliers within Belgium is rather uniform with somewhat higher percentage values here and there. The latter are mainly caused by IC outliers, since those contribute the most to the overall outlier percentage values in each grid cell. In Austria, grid cell percentages range from 0.1 up to $33 \%$. The majority of the grid cells have low outlier percentage values, except in the southwest corner. This is exactly the place where the Alps disturb the radar observations, leading to an increase in outliers with the employed method. From Fig. 5a and b we conclude that there is no real 

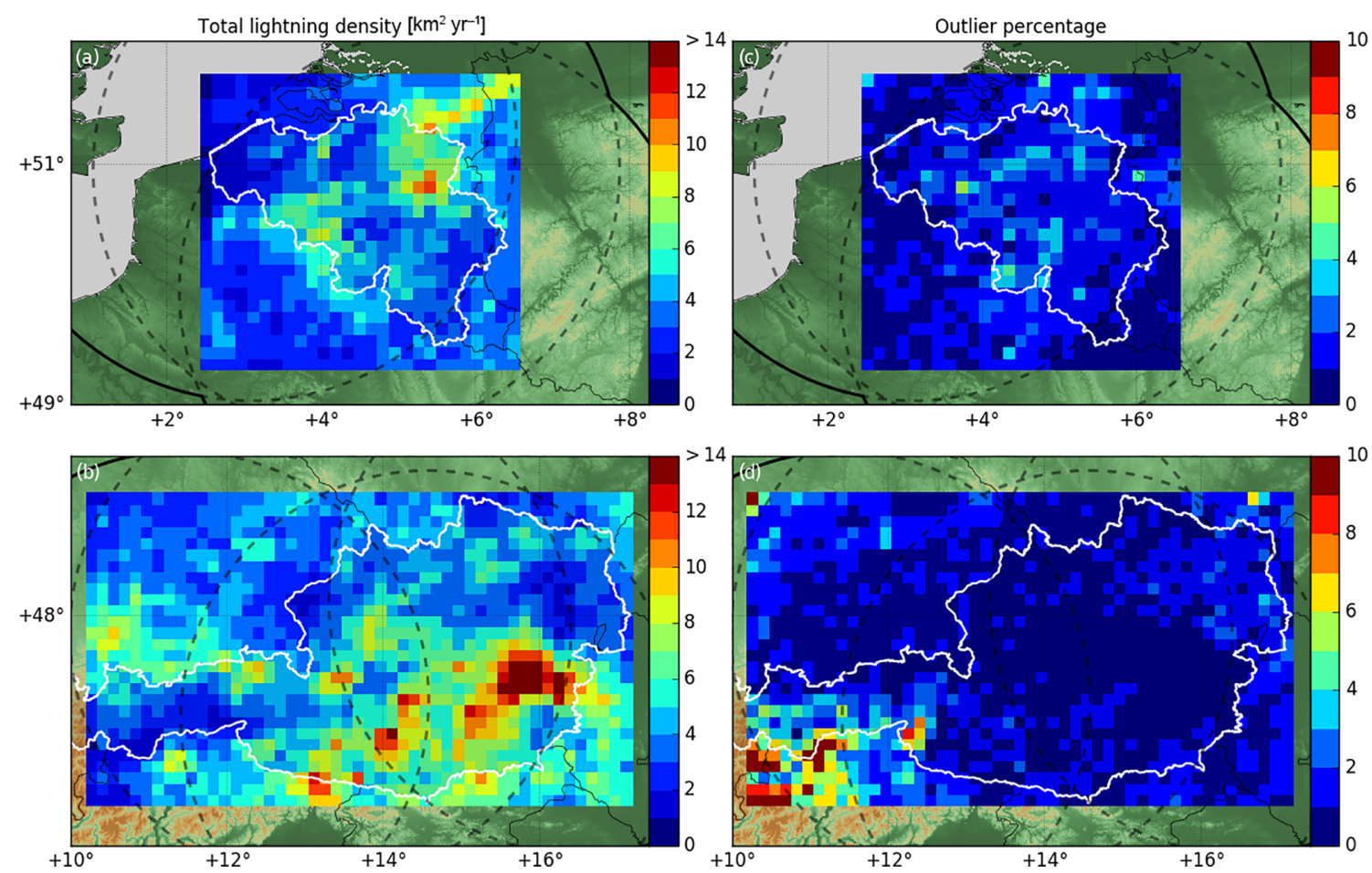

Figure 5. Panels (a, b) display the 6-year mean annual total lightning event (CG strokes + IC pulses) density on a $10 \mathrm{~km}^{2} \times 10 \mathrm{~km}^{2}$ grid in Belgium (top) and Austria (bottom), whereas the spatial distribution of the total percentage of outliers is plotted in (c, d) for an adopted search radius of $2 \mathrm{~km}$.

correlation between the total lightning event density and the spatial distribution of outliers.

Figure 6 illustrates the monthly variation of the percentage of outliers. An obvious decrease is observed in the percentage of outliers during May-September, compared to the other months of the year. This feature could be related to the fact that more sensor upgrades occur during winter or because precipitation of winter thunderstorms is more difficult to detect with the weather radars. In addition, the 3-D structure of lightning flashes in winter compared to summer is somewhat different (Lopez et al., 2017), which could increase the difficulty of locating those in winter accurately. Regarding the sensor upgrades, they often result in disabled angle information because systematic angle errors, i.e., site errors, are at first unknown and the correction takes a while because lightning data are necessary. Consequently, upgraded sensors start operating with disabled angle information during winter months. With respect to the observation of precipitation, during summer most of the storms are associated with large amounts of precipitation in vertically extended clouds, meaning that these storms are always very well detected by the radars. In contrast, winter storms are generally associated with less intense precipitation cells and with smaller vertical extensions. In some cases, winter storms are not detected by the radars at long range. In that case, lightning events produced by such undetected winter storms are wrongly classified as outliers. In contrast, an incorrect classification may also occur when a wrong detection appears by chance in a precipitation area detected by the radar. In this case, a wrong lightning detection is classified as a correct detection. Since radars generally detect less precipitation in winter than in summer (e.g., Hazenberg et al., 2011), such misclassification occurs less in winter than in summer, which means that the classification method will produce more outliers in winter. Thus, the reduced efficiency of precipitation detected by the weather radars in winter is an additional possible source of the observed increase of outlier classifications in winter. Note that Poelman et al. (2016) showed that on average peak current estimates of winter lightning are higher than those in summer. One would therefore expect that on average in winter more sensors participate in a lightning event compared to summer, resulting in a good location accuracy. Nevertheless, the absolute number of outliers during winter is much smaller compared to summer, as can be deduced from Fig. 3b. Thus, the increase in the percentage of outliers may not be too important for the majority of applications.

Figure 7 plots the outlier percentages related to each individual group; e.g., the percentage of negative IC outliers is related to the total number of negative IC pulses. Proportionally, the degree of occurrence of positive and negative outliers is of the same level, except for 2011, and follows the annual variation as in Fig. 4. Positive CG strokes exhibit the highest percentage of outliers in Belgium and Austria. This could be related to the fact that positive CG strokes are of- 

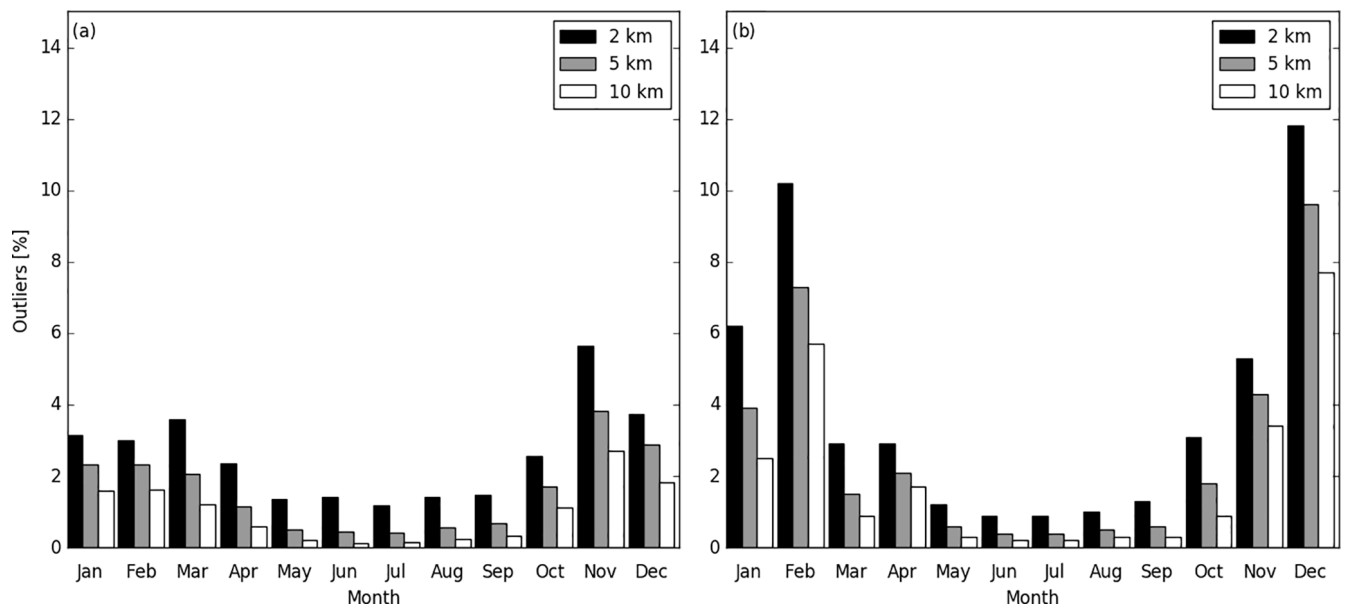

Figure 6. Monthly distribution of the total $(\mathrm{CG}+\mathrm{IC})$ percentage of outliers in (a) Belgium and (b) Austria for search radii of 2,5 and $10 \mathrm{~km}$.
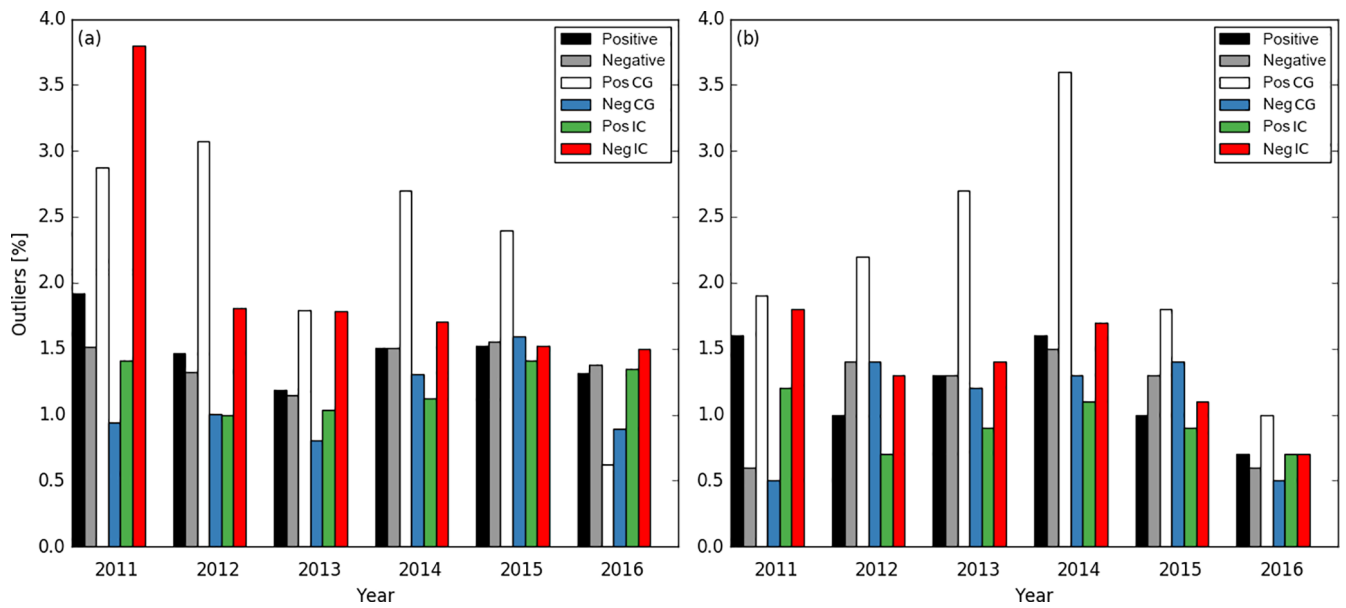

Figure 7. Percentage of outliers versus event type in (a) Belgium and (b) Austria for a search radius of $2 \mathrm{~km}$.

ten accompanied by significant IC activity complicating the transmitted electromagnetic fields (Fuquay, 1982; Saba et al., 2009). It is therefore harder to detect and correctly locate such strokes, resulting in a higher percentage of outliers. Furthermore, the percentage of negative CG outliers is roughly half of that of the positive CG outliers for the years 20112014. The opposite is found in the case of IC pulses, where the percentage of negative IC outliers is higher compared to the positive counterpart. However, the difference between positive and negative CG outliers and/or IC pulses decreases in 2015 and 2016. Thus, the percentage of outliers is more or less unrelated to the polarity of the event. In 2016, it is obvious that the outlier percentages of the individual types are more or less in line with each other. This could also be a result of the improved performance of the latest adopted location algorithm.

In Fig. 8, the percentage of outliers for peak current intervals up to $\pm 20 \mathrm{kA}$ is plotted and calculated with respect to the total amount of discharges within each peak current inter- val. It is seen that the distribution corresponds well between Belgium and Austria. Because positive CG strokes with peak currents below $5 \mathrm{kA}$ are categorized as IC, no data for positive CG below $5 \mathrm{kA}$ exist. First of all, the majority of the outliers for positive CG and IC discharges are found between $[5,10] \mathrm{kA}$ and $[0,5] \mathrm{kA}$, respectively, with a decline towards the larger peak current intervals. This is not surprising since the higher the peak current, the more sensors participate on average in locating the event. This is also true for negative IC outliers, whereas negative CG outliers have the highest percentage in the $[-10,-5] \mathrm{kA}$ range. Except for the $[-5,0] \mathrm{kA}$ interval, the percentages are similar between negative IC and CG outliers. This is not the case for the positive IC and CG outliers. In addition to what is plotted in Fig. 8, it is found that the percentage of CG outliers with absolute peak currents above $20 \mathrm{kA}$ is a factor of about 3 lower compared to the total percentage of outliers found within $|0-20| \mathrm{kA}$ and a factor of 15 lower in the case of IC. The larger drop in the case of IC results from the lower amount of IC events 

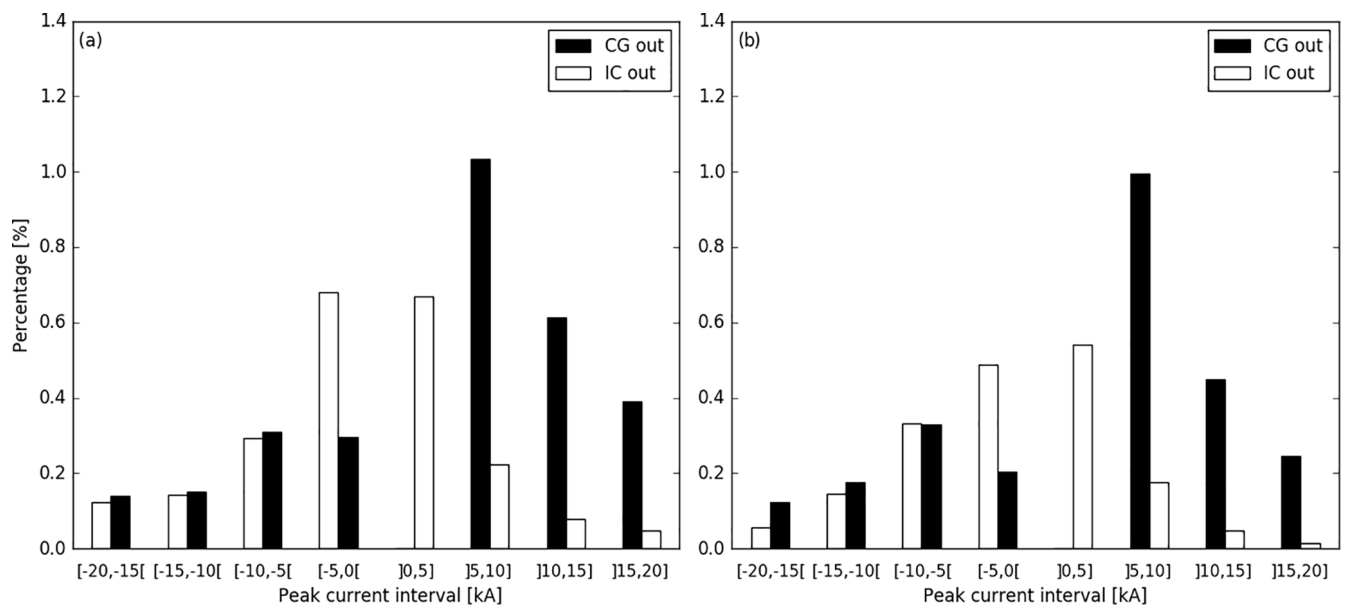

Figure 8. Percentage of outliers as a function of peak current in (a) Belgium and (b) Austria for a search radius of $2 \mathrm{~km}$.

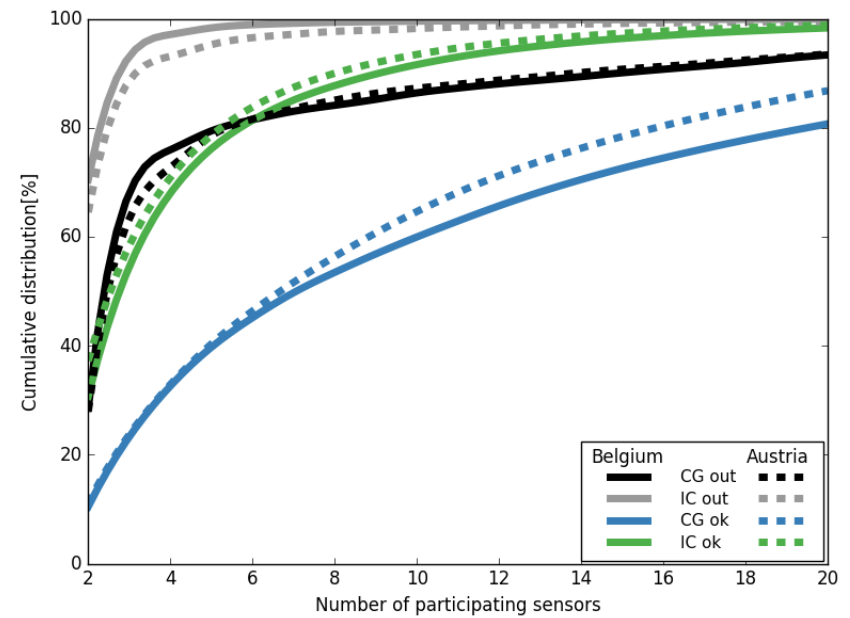

Figure 9. Cumulative distribution of the number of sensors participating in a solution for CG and IC outliers ("out") and correctly located ("ok") events.

with absolute peak currents larger than $20 \mathrm{kA}$ compared to CG events.

Figure 9 reveals the cumulative distribution of the number of sensors participating in a solution as a function of event type. First of all, one notices that in the case of CG strokes more sensors participate in a solution compared to IC events. This is attributed to the fact that in the LF range the amplitude of even the largest IC pulses is significantly lower compared to that of the CG return strokes (Weidman et al., 1981). The amplitude difference between CG strokes and IC pulses increases even further with increasing propagation distance between the source and the lightning sensor (Cooray et al., 2000). Hence, more sensors will detect the radiation from a single CG discharge compared to an IC pulse. The resemblance in distribution between Belgium and Austria is not surprising since the lightning sensors in EUCLID are quite

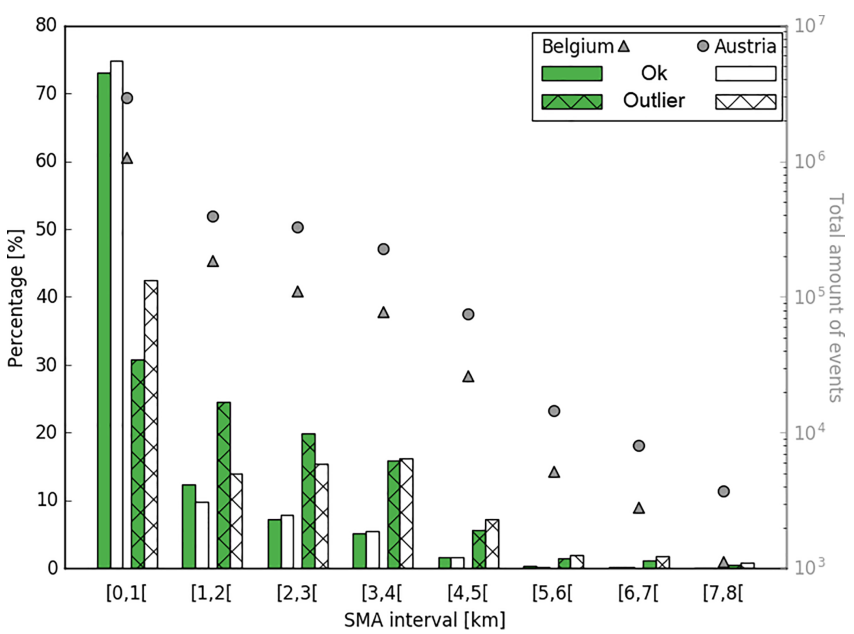

Figure 10. Distribution of the semi-major axis (SMA) of the outliers and "ok" events in Belgium and Austria for a search radius of $2 \mathrm{~km}$. In addition, the total amount of events per SMA interval is indicated as grey triangles (Belgium) and circles (Austria).

homogeneously distributed across the network. In addition, more sensors participate in the location of discharges that are correctly located than is the case of CG and IC outlier events. For instance, $85 \%$ of the IC outliers are located by two or three sensors, whereas this drops to $50 \%$ for correctly located IC pulses. For CG strokes on the other hand, only $20 \%$ of the outliers are located with more than six participating sensors, whereas this is the case for more than $60 \%$ for the CG strokes within $2 \mathrm{~km}$ of the nearest precipitation. We find that the median number of sensors participating in a solution for correctly located CG strokes and IC pulses is eight and three, respectively, and this drops to three and two participating sensors in the case of CG and IC outliers.

The central processor assigns a value of the semi-major axis of the $50 \%$ confidence ellipse to each lightning event. 

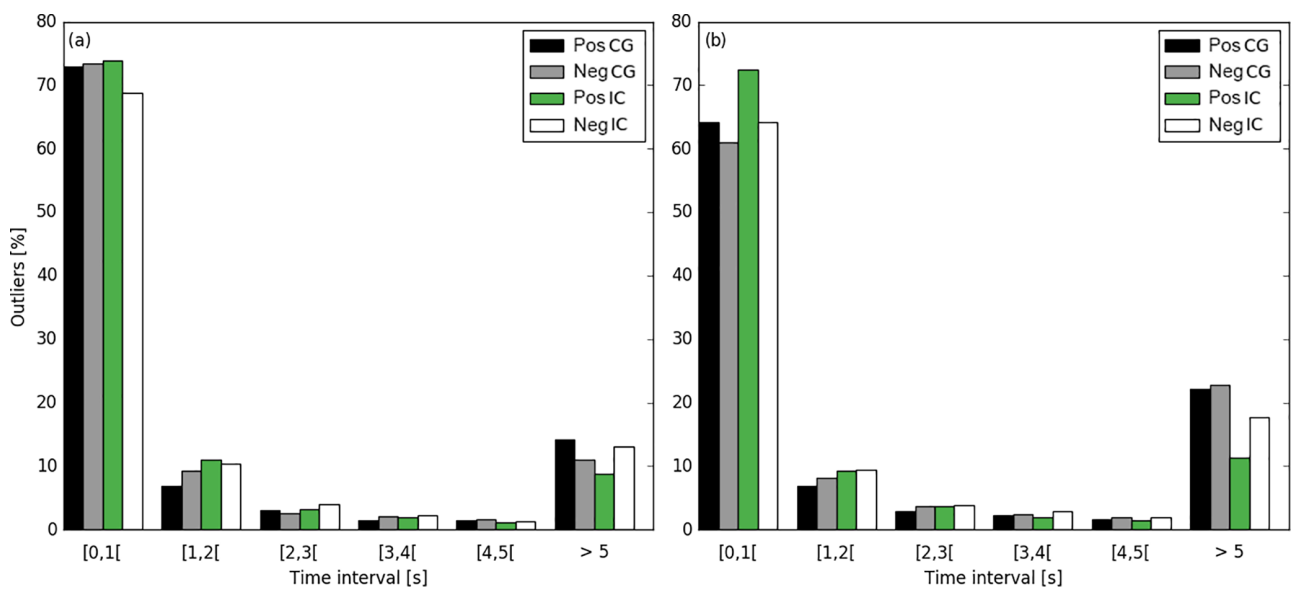

Figure 11. Distribution of the time difference between the outliers and their closest (in time) correctly located event in (a) Belgium and (b) Austria.

This value can be used as a quality indicator of the location accuracy, with smaller values indicating a larger confidence in the assigned location of the event. The distribution of SMA for all the events $(\mathrm{CG}+\mathrm{IC})$ is plotted in Fig. 10, separated into and normalized to outlier and correctly located events. In addition, the total number of events per SMA interval for Belgium and Austria is indicated. Note that events with an SMA larger than $7.5 \mathrm{~km}$ do not exist in the data since those events are regarded as bad quality events and hence rejected by the location algorithm. First of all, it is striking that the SMA distribution is almost equal for Belgium and Austria. The majority of "ok" events, i.e., $75 \%$, have SMA values falling in the $0-1 \mathrm{~km}$ range, whereas this drops to $40 \%$ in the case of outliers. The average and median value of the SMA for "ok" events are 775 and $200 \mathrm{~m}$, respectively, and this increases to 1.83 and $1.48 \mathrm{~km}$ in the case of outliers. Although not shown in this plot, it is found that the average SMA for CG strokes is smaller by a factor of 2 compared to IC pulses. This is expected since more sensors participate in a solution for CG strokes compared to IC pulses as discussed in Fig. 9.

Looking at Figs. 8 to 10 one could wonder whether the CG outliers could be simply considered as IC discharges misclassified by the network, since IC discharges have on average lower peak currents and hence a lower number of contributing sensors and therefore smaller SMA. Although this can be partly true, a considerable fraction of the CG outliers are found to have large peak currents. It is therefore unlikely that all the CG outliers are in fact misclassified IC discharges.

Up to now, lightning discharges have been classified into either correctly located strokes or outliers based on their distance to the nearest precipitation. However, using an additional time criterion it is possible to further dissociate the outliers into isolated outliers in space and time from those that are just wrongly located from a group of correctly located events. Figure 11 plots the distribution of the time difference between the outliers and their closest (in time) correctly lo- cated event. Once more, the distribution is found to be similar in Belgium and Austria. The majority of the outliers occur within $1 \mathrm{~s}$ of a correctly located event. One could argue that these are simply bad located lightning events, whereas those that take place after $1 \mathrm{~s}$ are so-called ghost outliers, i.e., outliers in time and space. Furthermore, from this plot it is found that the outliers behave quite independently of polarity and classification in Belgium and Austria.

\section{Summary}

In this study all lightning events detected by the EUCLID network during 2011 and 2016 that fall within selected areas in and around Belgium and Austria are classified as outliers or correctly located events based on their distance $\Delta r$ to the nearest precipitation. The latter two regions were chosen specifically for their difference in topography and because high spatial and temporal resolution radar data were readily available. A similar approach can be performed in the future on a larger spatial scale based for instance on the radar composite imagery produced by the Eumetnet Operational Programme for the Exchange of Weather Radar Information (OPERA, Huuskonen et al., 2014) and related EUCLID domain.

The applied methodology makes use of radar data with an adopted lower reflectivity threshold of $12 \mathrm{dBZ}$. Hence, precipitation is required to discriminate between the outliers and well-located lightning events. Therefore lightning produced by "dry" thunderstorms or bolts from the blue will be misclassified as outliers. However, these particular phenomena are extremely limited and do not influence the results presented in this study to a large extent. We believe that a methodology based on satellite cloudiness products would not allow a proper identification of outliers since cloudiness in Belgium and Austria is mostly not associated with thunderstorms. 
Categorizing the lightning events based on radar reflectivity data and comparing the results from different geographical regions is not a straightforward task. The reason for this is the potential calibration issues in the different radar networks with possibly different technology and local beam blockage problems, especially in the mountainous regions in Austria. A workaround, at least for the last problem, is the use of composite radar data. Despite these difficulties the overall results in both regions agree quite well. The overall percentage of outliers for both regions varies annually between 0.8 and $1.7 \%$ for a distance $\Delta r$ to the nearest precipitation of $2 \mathrm{~km}$ and drops further when a more relaxed $\Delta r$ is chosen. These values are the lower limits since it is possible that an outlier is located in an area with rain. The percentage of outliers is quite small, having in mind that a $\Delta r$ of $2 \mathrm{~km}$ is already quite a strict criterion. Outside the European summer thunderstorm season, the percentage of outliers tends to increase somewhat. Amongst some of the sources responsible for this increase is the fact that more sensor upgrades occur during winter or that the radar underestimates precipitation to some extent. In addition, the 3-D structure of flashes is somewhat different in winter compared to summer, which could increase the difficulty of locating them accurately. The majority of all the outliers are low peak current events with absolute values falling between 0 and $10 \mathrm{kA}$. More specifically, positive CG strokes are more likely to be classified as outliers compared to all other types of discharges. Furthermore, it turns out that the number of sensors participating in locating a lightning discharge is different for outliers versus correctly located events, with outliers having the lowest amount of sensors participating. In addition, it is found that, in general, the SMA of non-outliers is much smaller compared to the SMA belonging to outliers.

Data availability. All data used in this work are available from the authors upon request (dieter.poelman@meteo.be).

Competing interests. The authors declare that they have no conflict of interest.

Acknowledgements. The authors would like to thank the reviewers for their constructive remarks and suggestions, which have improved the paper. We further thank the EUCLID consortium for providing the EUCLID data in this study.

Edited by: Andrew Sayer

Reviewed by: Kleber Naccarato and two anonymous referees

\section{References}

Azadifar, M., Rachidi, F., Rubinstein, M., Paolone, M., Diendorfer, G., Pichler, H., Schulz, W., Pavanello, D., and Romero, C.: Evaluation of the performance characteristics of the European Lightning Detection Network EUCLID in the Alps region for upward negative flashes using direct measurements at the instrumented Säntis Tower, J. Geophys. Res.-Atmos., 121, 595-606, https://doi.org/10.1002/2015JD024259, 2016.

Biagi, C. J., Cummins, K. L., Kehoe, K. E., and Krider, E. P.: National Lightning Detection Network (NLDN) performance in southern Arizona, Texas, and Oklahoma in 2003-2004, J. Geophys. Res., 112, D05208, https://doi.org/10.1029/2006JD007341, 2007.

Cramer, J. A. and Cummins, K. L.: Evaluating location accuracy of lightning location networks using tall towers, in: 23rd International Lightning Detection Conference \& 5th International Lightning Meteorology Conference, Vaisala Inc., Tucson, Arizona, 2014.

Cooray, V., Fernando, M., Sörensen, T., Götschl, T., and Pedersen, A.: Propagation of lightning generated transient electromagnetic fields over fintely conducting ground, J. Atmos. Terr. Phys., 62, 583-600, 2000.

Cummins, K., Murphy, M., Bardo, E., Hiscox, R., Pyle, W. L., and Pifer, A.: A combined TOA/MDF technology upgrade of the U.S. National Lightning Detection Network, J. Geophys. Res., 103, 9035-9044, 1998.

Cummins, K., Cramer, J., Biagi, C., Krider, E., Jerauld, J., Uman, M., and Rakov, V.: The U.S. National Lightning Detection Network: Post-upgrade status, Second Conference on Meteorological Applications of Lightning Data, Atlanta, Georgia, American Meteorological Society, 2006.

Defer, E., Pinty, J.-P., Coquillat, S., Martin, J.-M., Prieur, S., Soula, S., Richard, E., Rison, W., Krehbiel, P., Thomas, R., Rodeheffer, D., Vergeiner, C., Malaterre, F., Pedeboy, S., Schulz, W., Farges, T., Gallin, L.-J., Ortéga, P., Ribaud, J.-F., Anderson, G., Betz, H.-D., Meneux, B., Kotroni, V., Lagouvardos, K., Roos, S., Ducrocq, V., Roussot, O., Labatut, L., and Molinié, G.: An overview of the lightning and atmospheric electricity observations collected in southern France during the HYdrological cycle in Mediterranean EXperiment (HyMeX), Special Observation Period 1, Atmos. Meas. Tech., 8, 649-669, https://doi.org/10.5194/amt-8-649-2015, 2015.

Diendorfer, G., Mair, M., Schulz, W., and Hadrian, W.: Lightning current measurements in Austria - Experimental setup and first results, in: 25th Intl. Conf. on Lightning Protection, 44-47, ICLP Centre, Rhodes, Greece, 2000a.

Diendorfer, G., Schulz, W., and Mair M.: Evaluation of a LLS based on lightning strikes to an instrumented tower, in: 16th International Lightning Detection Conference, Tucson, Ariz., $2000 \mathrm{~b}$.

Fuquay, D. M.: Positive cloud-to-ground lightning in summer thunderstorms, J. Geophys. Res.-Ocean., 87, 7131-7140, 1982.

Goudenhoofdt, E. and Delobbe, L.: Generation and verification of rainfall estimates from 10-yr volumetric weather radar measurements, J. Hydrometeorol., 17, 1223-1242, 2016.

Hazenberg, P., Leijnse, H., and Uijlenhoet, R.: Radar rainfall estimation of stratiform winter precipitation in the Belgian Ardennes, Water Resour. Res., 47, W02507, https://doi.org/10.1029/2010WR009068, 2011. 
Heidler, F. and Schulz, W.: Lightning current measurements compared to data from the lightning location system BLIDS, in: International Colloquium on Lightning and Power Systems (CIGRE), Bologna, Italy, 2016.

Huuskonen, A., Saltikoff, E., and Holleman, I.: The Operational Weather Radar Network in Europe, B. Am. Meteorol. Soc., 95, 897-907, 2014

Jerauld, J., Rakov, V. A., Uman, M. A., Rambo, K. J., Jordan, D. M., Cummins, K. L., and Cramer, J. A.: An evaluation of the performance characteristics of the U.S. National Lightning Detection Network in Florida using rocket-triggered lightning, J. Geophys. Res., 110, D19106, https://doi.org/10.1029/2005JD005924, 2005.

Kaltenboeck, R.: New generation of dual polarized weather radars in Austria, in: 7th Euoprean Conference on Radar in Meteorology and Hydrology (ERAD), Toulouse, France, ERAD, 2012a.

Kaltenboeck, R.: Das österreichische Wetterradarnetzwerk, OEGM Bull., 2, 14-22, 2012b.

Kaltenboeck, R. and Steinheimer, M.: Radar-based severe storm climatology for Austrian complex orography related to vertical wind shear and atmospheric instability, Atmos. Res., 158-159, 216-230, 2015.

Lopez, J. A., Pineda, N., Montanya, J., van der Velde, O., Fabro, F., and Romero, D.: Spatio-temporal dimension of lightning flashes based on three-dimensional Lightning Mapping Array, Atmos. Res., 197, 255-264, 2017.

Mallick, S., Rakov, V., Ngin, T., Gamerota, W., Pilkey, J., Hill, J., Uman, M., Jordan, D., Nag, A., and Said, R.: Evaluation of the GLD360 performance characteristics using rocket-and-wire triggered lightning data, Geophys. Res. Lett., 41, 3636-3642, https://doi.org/10.1002/2014GL059920, 2014a.

Mallick, S., Rakov, V. A., Hill, J. D., Ngin, T., Gamerota, W. R., Pilkey, J. T., Biagi, C. J., Jordan, D. M., Uman, M. A., Cramer, J. A., and Nag, A.: Performance characteristics of the NLDN for return strokes and pulses superimposed on steady currents, based on rocket-triggered lightning data acquired in Florida in 2004-2012, J. Geophys. Res.-Atmos., 119, 38253856, https://doi.org/10.1002/2013JD021401, 2014b.

Mallick, S., Rakov, V. A., Hill, J. D., Ngin, T., Gamerota, W. R., Pilkey, J. T., Jordan, D. M., Uman, M. A., Heckman, S., Sloop, C. D., and Liu, C.: Performance characteristics of the ENTLN evaluated using rocket-triggered lightning data, Electr. Pow. Syst. Res., 118, 15-28, https://doi.org/10.1016/j.epsr.2014.06.007, 2014c.

Marschall, J. S. and Palmer, W. Mc K.: The distribution of raindrop size, J. Meteorol., 5, 165-166, 1948.

Murphy, M. J. and Cummins, K. L.: Two-dimensional and threedimensional cloud discharge detection, presented at the Int. Lightning Detection Conf., Tucson, AZ, 1998.

Nag, A., Mallick, S., Rakov, V. A., Howard, J. S., Biagi, C. J., Hill, J. D., Uman, M. A., Jordan, D. M., Rambo, K. J., Jerauld, J. E., DeCarlo, B. A., Cummins, K. L., and Cramer, J. A.: Evaluation of US National Lightning Detection Network performance characteristics using rocket-triggered lightning data acquired in 2004-2009, J. Geophys. Res., 116, D02123, https://doi.org/10.1029/2010JD014929, 2011.

Nag, A., Murphy, M. J., Schulz, W., and Cummins, K. L.: Lightning Location Systems: Insights on characteristics and validation techniques, Earth Sp. Sci., 2, 65-93, 2015.
Orville, R., Huffines, G., Burrows, W., Holle, R., and Cummins, K.: The North American Lightning Detection Network (NLDN) First results: 1998-2000, Mon. Weather Rev., 130, 2098-2108, 2002.

Pavanello, D., Rachidi, F., Janischewskyj, W., Rubinstein, M., Shostak, V., Nucci, C. A., Cummins, K. L., Hussein, A. M., and Chang, J. S.: On the current peak estimates provided by lightning detection networks for lightning return strokes to tall towers, IEEE Trans. Electromagn. C., 51, 453-458, 2009.

Poelman, D. R., Schulz, W., and Vergeiner, C.: Performance characteristics of distinct lightning detection networks covering Belgium, J. Atmos. Ocean. Tech., 30, 942-951, https://doi.org/10.1175/JTECH-D-12-00162.1, 2013a.

Poelman, D. R., Honoré, F., Anderson, G., and Pedeboy, S.: Comparing a regional, subcontintental, and long-range lightning location system over the Benelux and France, J. Atmos. Ocean. Tech., 30, 2394-2405, https://doi.org/10.1175/JTECH-D-12-00263.1, 2013b.

Poelman, D. R., Schulz, W., Diendorfer, G., and Bernardi, M.: The European lightning location system EUCLID - Part 2: Observations, Nat. Hazards Earth Syst. Sci., 16, 607-616, https://doi.org/10.5194/nhess-16-607-2016, 2016.

Pohjola, H. and Mäkelä, A.: The comparison of GLD360 and EUCLID lightning location systems in Europe, Atmos. Res., 123, 117-128, 2013.

Rison, W., Thomas, R. J., Krehbiel, P. R., Hamlin, T., and Harlin, J.: A GPS-based three-dimensional lightning mapping system: initial observations in central New Mexico, Geophys. Res. Lett., 26, 3573-3576, 1999.

Romero, C., Paolone, M., Rachidi, F., Rubinstein, M., Rubinstein, A., Diendorfer, G., Schulz, W., Bernardi, M., and Nucci, C. A.: Preliminary comparison of data from the säntis tower and the euclid lightning location system, XIth International Symposium on Lightning Protection (SIPDA), 3-7 October, Fortaleza, Brazil, 2011.

Saba, M. M. F., Campos, L. Z. S., Krider, E. P., and Pinto, O. J.: High-speed video observations of positive ground flashes produced by intracloud lightning, Geophys. Res. Lett., 36, L12811, https://doi.org/10.1029/2009GL038791, 2009.

Said, R., Inan, U., and Cummins, K.: Long-range lightning geolocation using a VLF radio atmospheric waveform bank, J. Geophys Res., 115, D23108, https://doi.org/10.1029/2010JD013863, 2010.

Schulz, W., Vergeiner, C., Pichler, H., Diendorfer, G., and Packet, S.: Validation of the Austrian Lightning Location System ALDIS for negative flashes, in: Proc. CIGRE Symposium, Sarajevo, Bosnia and Herzegovina, CIGRE, 2012.

Schulz, W., Pichler, H., Diendorfer, G., Vergeiner, C., and Pack, S.: Validation of detection of positive flashes by the Austrian Lightning Location System (ALDIS), in: 12th Intl. Symposium on Lightning Protection (XII SIPDA), paper 2.2, Belo Horizonte, Brazil, 2013.

Schulz, W., Diendorfer, G., Pedeboy, S., and Poelman, D. R.: The European lightning location system EUCLID - Part 1: Performance analysis and validation, Nat. Hazards Earth Syst. Sci., 16, 595-605, https://doi.org/10.5194/nhess-16-595-2016, 2016.

Thomas, R. J., Krehbiel, P. R., Rison, W., Hunyady, S. J., Winn, W. P., Hamlin, T., and Harlin, J.: Accuracy of the 
lightning mapping array, J. Geophys. Res., 109, D14207, https://doi.org/10.1029/2004JD004549, 2004.

van der Velde, O. and Montanya, J.: Asymmetries in bidirectional leader development of lightning flashes, J. Geophys. Res.Atmos., 118, 504-513, https://doi.org/10.1002/2013JD020257, 2013.

Wacker, R. and Orville, R.: Changes in measured lightning flash count and return stroke peak current after the 1994 U.S. National Lightning Detection Network Upgrade: 1. Observations, J. Geophys. Res., 104, 2151-2157, 1999a.
Wacker, R. and Orville, R.: Changes in measured lightning flash count and return stroke peak current after the 1994 U.S. National Lightning Detection Network Upgrade: 2. Theory, J. Geophys. Res., 104, 2159-2162, 1999b.

Weidman, C. D., Krider, E. P., and Uman, M. A.: Lightning amplitude spectra in the intveral from $100 \mathrm{kHz}$ to $20 \mathrm{MHz}$, Geophys. Res. Lett., 8, 931-934, 1981. 